\title{
Médiévales
}

Langues, Textes, Histoire

55 | automne 2008

Usages de la Bible

\section{Hélène NOIZET, La Fabrique de la ville. Espaces et sociétés à Tours (IX ${ }^{e}$-XIII ${ }^{e}$ siècles), Paris, Publications de la Sorbonne, 2007, $504 \mathrm{p}$.}

Olivier Méry

\section{OpenEdition}

\section{Journals}

Édition électronique

URL : http://journals.openedition.org/medievales/5506

DOI : 10.4000/medievales.5506

ISSN : 1777-5892

\section{Éditeur}

Presses universitaires de Vincennes

\section{Édition imprimée}

Date de publication : 20 décembre 2008

Pagination : 175-178

ISBN : $978-2-84292-221-4$

ISSN : 0751-2708

Référence électronique

Olivier Méry, "Hélène noIzet, La Fabrique de la ville. Espaces et sociétés à Tours (Ixe-xIII siècles), Paris, Publications de la Sorbonne, 2007, 504 p. », Médiévales [En ligne], 55 | automne 2008, mis en ligne le 08 mai 2009, consulté le 22 septembre 2020. URL : http://journals.openedition.org/medievales/5506 ; DOI : https://doi.org/10.4000/medievales.5506

Ce document a été généré automatiquement le 22 septembre 2020.

Tous droits réservés 


\title{
Hélène NOIZET, La Fabrique de la ville. Espaces et sociétés à Tours (IX ${ }^{e}$-XIII ${ }^{e}$ siècles), Paris, Publications de la Sorbonne, 2007, 504 p.
}

\author{
Olivier Méry
}

1 Cet ouvrage est la version remaniée d'une thèse soutenue en 2003 à l'université de Tours. Il s'agit d'une monographie urbaine, développant une analyse socio-spatiale de deux quartiers centraux de la ville. Deux remarques introductives s'imposent. Premièrement, la période considérée, de la fin du viII siècle au début du XIV siècle, n'est pas riche en études urbaines, plutôt consacrées aux derniers siècles du Moyen Âge. L'étude éclaire l'apogée de la croissance urbaine médiévale alors que cette période ne connait pas de définition claire de ce qu'est la ville. Il s'agit d'entrer dans les mécanismes du développement urbain par une étude de cas principalement basée sur un corpus de 221 chartes tirées de la riche documentation de Saint-Martin de Tours. La seconde remarque porte sur l'angle choisi pour observer cette construction de la ville, désignée par la notion de "fabrique urbaine ». Développé en géographie, ce concept correspond à la volonté d'expliquer l'urbanisation autrement qu'en se focalisant sur les projets ponctuels d'aménagement et d'urbanisme. Il permet d'explorer une dialectique de longue durée entre les activités sociales et un espace urbain qui n'est pas appréhendé comme un reflet strict de la société mais comme le résultat d'une accumulation. Ce long processus doit moins à des entreprises volontaristes qu'aux effets induits des actions de différents acteurs et habitants, lesquels actes peuvent avoir une finalité initiale bien éloignée de l'aménagement urbain. Le processus de fabrique urbaine est séduisant car il renvoie bien à la nature impensée de la ville au Moyen Âge central et à son développement pluriséculaire issu des pratiques quotidiennes, des représentations des citadins et des institutions.

2 L'étude se décompose en cinq parties, les quatre premières correspondent à un découpage chronologique tandis que la dernière amène des conclusions plus globales. 
Chacun de ses épisodes chronologiques suit la même démarche : l'activité des différents acteurs, pouvoirs royal ou locaux, moines ou chanoines, ainsi que les interactions entre ces individus, sont à la fois influencées par l'organisation spatiale et productrices d'espace. Cet examen précède l'analyse lexicographique du vocabulaire spatial, différencié selon les auteurs des documents, ce qui permet de comprendre comment les représentations liées aux dénominations de l'espace dérivent d'enjeux géographiques des interactions entre acteurs. Outre son aspect heuristique, cette démarche permet de présenter les analyses sous la forme d'un récit qui fait de cet ouvrage moins une reconstitution figée du parcellaire médiéval que l'occasion d'une réflexion sur la construction matérielle et identitaire de la ville.

3 À partir de 774 , le pouvoir carolingien participe activement à la définition de la communauté de Saint-Martin et à l'adoption d'une règle canoniale. Cette formalisation de l'organisation de Saint-Martin a des implications spatiales, mettant fin à la cohabitation dans un même espace de moines et de chanoines. Elle va de pair avec la mise en place d'un réseau de domaines destiné à répondre aux besoins du chapitre dont la forme par un effet de jeux d'échelles se répercute sur ce premier noyau de l'agglomération tourangelle. Durant le $\mathrm{Ix}^{\mathrm{e}}$ siècle, les comtes Robertiens, abbés laïcs de Saint-Martin, exercent une influence croissante sur les rapports de force entre titulaires des différents offices canoniaux ce qui introduit progressivement des brèches dans la cohésion du chapitre, répercutées dans sa configuration spatiale. Les mots employés pour désigner la ville et ses lieux forment une variable importante du dialogue au sein du triptyque roi-comte-chanoines, ainsi que dans les relations internes au chapitre de Saint-Martin.

4 À partir de 918, la situation devient plus complexe et Tours apparaît davantage comme une juxtaposition de noyaux qu'une unité. La géographie ecclésiale s'étoffe avec la refondation d'un ancien monastère dédié à saint Julien dans une zone vide intermédiaire entre la ville antique et Saint-Martin, l'implication de moines de Marmoutier dans le proche quartier de Châteauneuf et la création d'un castrum lié à l'immunité accordée à Saint-Martin. Non seulement les Robertiens puis les Capétiens ont favorisé cette nouvelle entité mais, concédant des chartes pour dynamiser l'activité économique ainsi que des fiefs aux vassaux du comte afin de mieux contrôler ce dernier, ils accentuent la fragmentation des droits au sein de Tours. Le vocabulaire spatial de cette période reflète la multipolarisation juridictionnelle de la ville ainsi que la forte compétition entre acteurs pour s'approprier l'identité d'un lieu. Quand les chanoines évoquent le nouveau castellum, ils mentionnent un castrum Sancti Martini là où les moines de Marmoutier utilisent le terme de castrum novum Sancti Martini. Ces deux expressions montrent une lutte pour capter l'héritage de Saint-Martin dont sont absents l'archevêque et les moines de Saint-Julien, lesquels emploient des termes comme suburbium Turonicae permettant d'affirmer la continuité spatiale et temporelle de la légitimité épiscopale à agir sur l'ensemble de la ville. Ce jeu ne se limite pas à des relations d'oppositions propices au morcellement de l'espace urbain. Ainsi les besoins des chanoines et des moines de Marmoutier favorisent commerce et artisanat autour de Saint-Martin tandis que le monastère de Saint-Julien maintient dans ses alentours un faible niveau d'urbanisation en garantissant une séparation nette entre moines et laïcs.

$5 \quad$ Le XII ${ }^{e}$ siècle représente le paroxysme de cette division de la ville. Il s'agit en premier lieu du moment d'affirmation d'une élite urbaine d'origine marchande et non 
nobiliaire. Si ces bourgeois ne forment pas un groupe homogène aux intérêts communs, la reconnaissance de leur existence participe à l'éclosion de conflits juridiques dont la lecture montre la variabilité des possibles configurations dans le paysage sociopolitique tourangeau. Ces rivalités ne sont pas seulement locales, elles sont alimentées par une deuxième caractéristique $d u$ XII $^{\mathrm{e}}$ siècle: la présence plus marquée du souverain capétien qui entend ainsi répondre aux Plantagenêts, devenus comtes d'Anjou à partir d'Henri II. Le chapitre de Saint-Martin, à travers la personne du trésorier, office fréquemment occupé par un membre de la famille capétienne, devient le pivot des enjeux politiques en agissant comme une interface entre trois acteurs : le roi, le comte et enfin le groupe des bourgeois, présent dans l'enclave martinienne. La toponymie et son insertion dans les sources se font l'écho de telles recompositions. Le castrum autour de Saint-Martin devient davantage un espace royal qu'un lieu approprié par les chanoines. Durant ce siècle, de nouveaux burgi et castri sont mentionnés, signe d'un développement démographique fragmenté, leur apparition démontre également des changements dans le rapport à l'espace. La mention de castra est plus fréquente pour qualifier les hommes que les biens, le toponyme est devenu plus neutre, circulant davantage entre les acteurs, il est davantage lié à l'activité sociale des bourgeois, privant ainsi les chanoines de la possibilité de participer au jeu social à travers une identité topographique.

Dernier moment de l'enquête, le XIII ${ }^{e}$ siècle marque l'établissement d'un nouvel équilibre qui favorise une stabilisation des territoires. À l'occasion d'un règlement entre le comte et le roi, le castrum de Saint-Martin est redéfini comme un territoire royal, dans la continuité de l'évolution du XII ${ }^{\mathrm{e}}$ siècle mais désormais cette appropriation exclut les chanoines qui apparaissent comme les habitants du claustrum. Cette nouvelle fracture est accentuée par la volonté des papes de réformer le chapitre martinien pour limiter l'absentéisme des chanoines, qui ont tendance à considérer leur charge de manière plus individuelle que collective. Il s'agit de renforcer l'aspect communautaire de Saint-Martin en recréant une barrière spatiale, sociale entre les bourgeois et les chanoines dont le mode de vie semble très laïcisé. Ces réformes récréent un espace identifié aux chanoines qui exclut autant les laïcs que le pouvoir royal. Ce dernier n'est pas le perdant de ces évolutions. Sa victoire sur le Plantagenêt lui permet de rassembler le reste de la ville sous l'autorité de son bailli et d'intervenir plus directement dans les rapports entre les chanoines et les bourgeois dans le sens d'une contractualisation accrue. Cette période est ainsi marquée par une forte approche juridique de l'espace à laquelle participe le changement dans le système de localisation des biens qui s'appuie désormais sur le fief et la paroisse devenus des référents spatiaux.

7 La dernière partie de l'ouvrage en est en fait la clé de voûte. L'analyse des structures parcellaires très contrastées de trois quartiers d'après le cadastre napoléonien mène à la définition d'idéaux-types au sens webérien, différenciant l'influence sur la morphologie urbaine de la longue présence des chanoines et des moines. Sans que l'un de ses deux protagonistes n'ait eu le projet de construire la ville, pas plus que les autres acteurs présents dans cette enquête, leurs activités ont autant pesé sur le cadre matériel de la ville qu'elles ont été influencées par celui-ci.

$8 \quad$ La multiplicité des pistes suivies est l'une des qualités essentielles de cette étude qui traite autant des aspects matériels de la ville que des représentations attachées aux espaces. En plaçant les jeux d'acteurs comme ossature d'un récit, Hélène Noizet se détache des causalités schématiques pour expliquer la morphogénèse urbaine de façon 
dynamique. C'est justement la pertinence et l'originalité de la méthodologie employée qui permet d'aborder le thème de la croissance urbaine dans son moment de plus forte intensité mais qui paradoxalement est resté peu étudié faute d'une approche satisfaisante. 